\title{
Inherited pericentric inversion of chromosome number two: A linkage study*
}

\author{
By L. R. WEITKAMP, M. K. JANZEN, S. A. GUTTORMSEN \\ AND H. GERSHOWITZ \\ Department of Human Genetics, University of Michigan Medical School, \\ Ann Arbor, Michigan
}

Pericentric inversion has been suggested as one possible explanation for an abnormally located, human somatic cell autosomal centromere in twenty-one instances (reviewed in Jacobs et al. 1967; see also Summitt \& Atnip, 1966; Nance \& Engel, 1967; Schmid, 1967; and Soudek, Laxová \& Adámek, 1968). Five of these cases involved chromosome no. 2 : three were found in individuals with various abnormalities (mild mental retardation and multiple congenital anomalies, DeGrouchy et al. 1963; mild mental retardation and hypogonadism, Miller, 1966, cited in Cohen, 1967; severe mental retardation and features of the de Lange syndrome, Breg, 1966, cited in Cohen, 1967) and two in normal individuals (Carr, 1962 ; Summitt \& Atnip, 1966). Summitt and Atnip also reported that the abnormal no. 2 chromosome occurred in the normal mother of the propositus and in two of her five normal siblings.

In this paper we report the occurrence, inheritance, segregation and genetic linkage relations of an abnormal number 2 chromosome. The most likely explanation for the abnormality is that it results from an asymmetric pericentric inversion, although formal proof of this is lacking. This is the first report of a study in which a cytologically recognizable abnormality of the number 2 chromosome was used to determine whether any one of the genetic loci controlling a number of serum proteins, red cell enzymes and red cell antigens is located on this chromosome.

\section{METHODS}

The proposita (kindred no. 10854) was identified during a routine cytologic examination to determine sex in a case of what was subsequently identified as adrenogenital syndrome. Karyotyping was done by direct microscopical observation of peripheral blood leukocytes cultured in Medium 1 A (Grand Island Biological Co., Grand Island, New York) and harvested using a modification of the technique of Moorehead et al (1960).

The red cell enzymes, adenylate kinase (AK), 6-phosphogluconate dehydrogenase (6-PGD), lactic dehydrogenase (LDH), malic dehydrogenase (MDH), phosphoglucomutase (PGM) and acid phosphatase (AP), were in each case separated by vertical starch gel electrophoresis (Electrostarch, Electrostarch Co., Madison, Wisconsin) at $\mathrm{pH} 7.0$ using a discontinuous buffer system (gel buffer $0 \cdot 005 \mathrm{M}$ histidine, bridge buffer $0.41 \mathrm{M}$ citric acid: both adjusted to $\mathrm{pH} 7 \cdot 0$ with sodium hydroxide). Gels which are developed for 6-PGD had $25 \mathrm{mg}$ NADP added per litre of cooked gel. Electrophoresis at $10 \mathrm{~V} / \mathrm{cm}$. was continued for 4-5 hr. in the gels which were developed for AK, 6-PGD, LDH and MDH and for 20-24 hr. in the gels which were developed for PGM and AP. Bands of enzymic activity were then visualized using an $0.75 \%$ agar gel overlay and the customary reagents for histochemical detection. Red cell antigen and

\footnotetext{
* Supported in part by the U.S. Atomic Energy Commission Contract AT(11-1)-1552.
} 
54 L. R. Weitkamp, M. K. Janzen, S. A. Guttormsen and H. Gershowitz

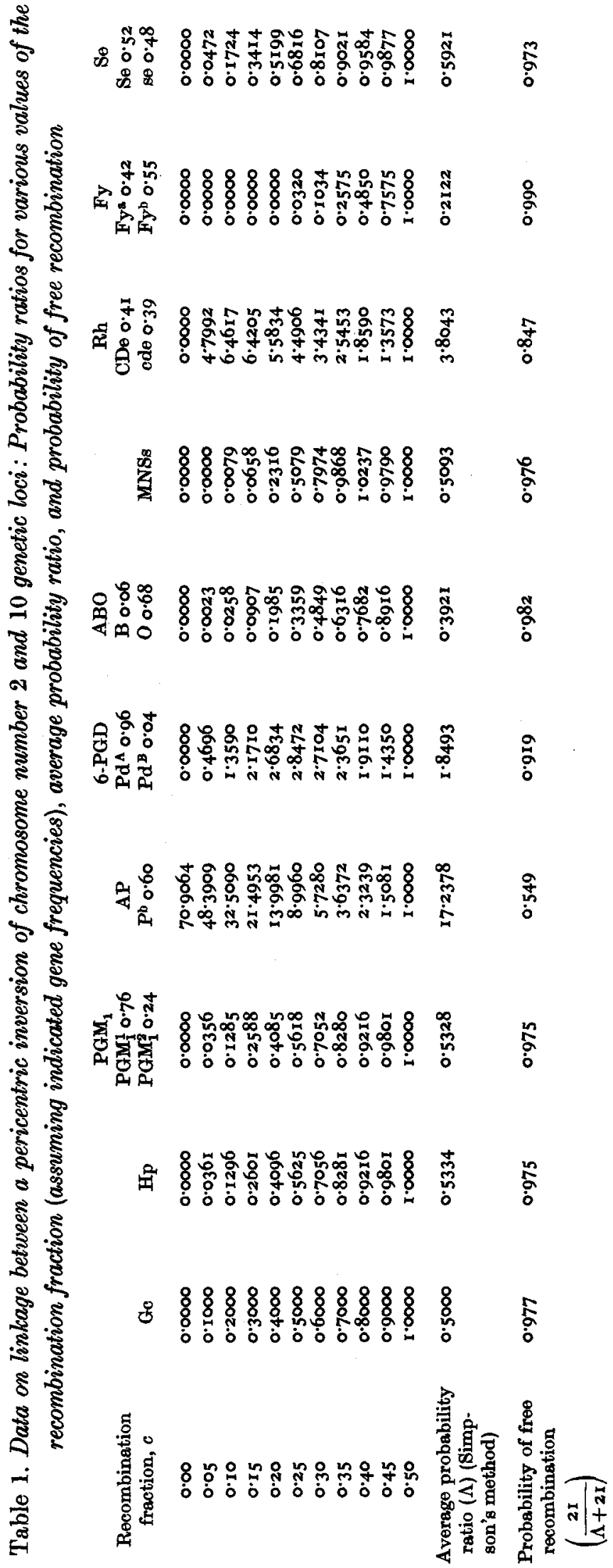


serum protein types were determined by currently standard procedures. Secretor phenotypes were deduced from the Lewis red cell phenotypes where possible.

The linkage analysis follows the pattern originally described by Haldane \& Smith (1947). Specifying $c$ as the recombination fraction and $b=1-c$ as the non-recombination fraction, the likelihood $(L)$ or algebraic probability expression for the occurrence of the segregation patterns of the marker chromosome and any particular genetic locus was computed by summing the probabilities of occurrence for each of the possible, genotypically different pedigrees consistent with the observed or assigned phenotypes in the pedigree. Where direct typing was not possible, genotype was assigned on the basis of the requirements, in terms of genetic segregation, for obtaining the phenotypes of the tested offspring of an individual. When a unique genotype was not specifiable in this manner, a probability for each of the possible genotypes for a given

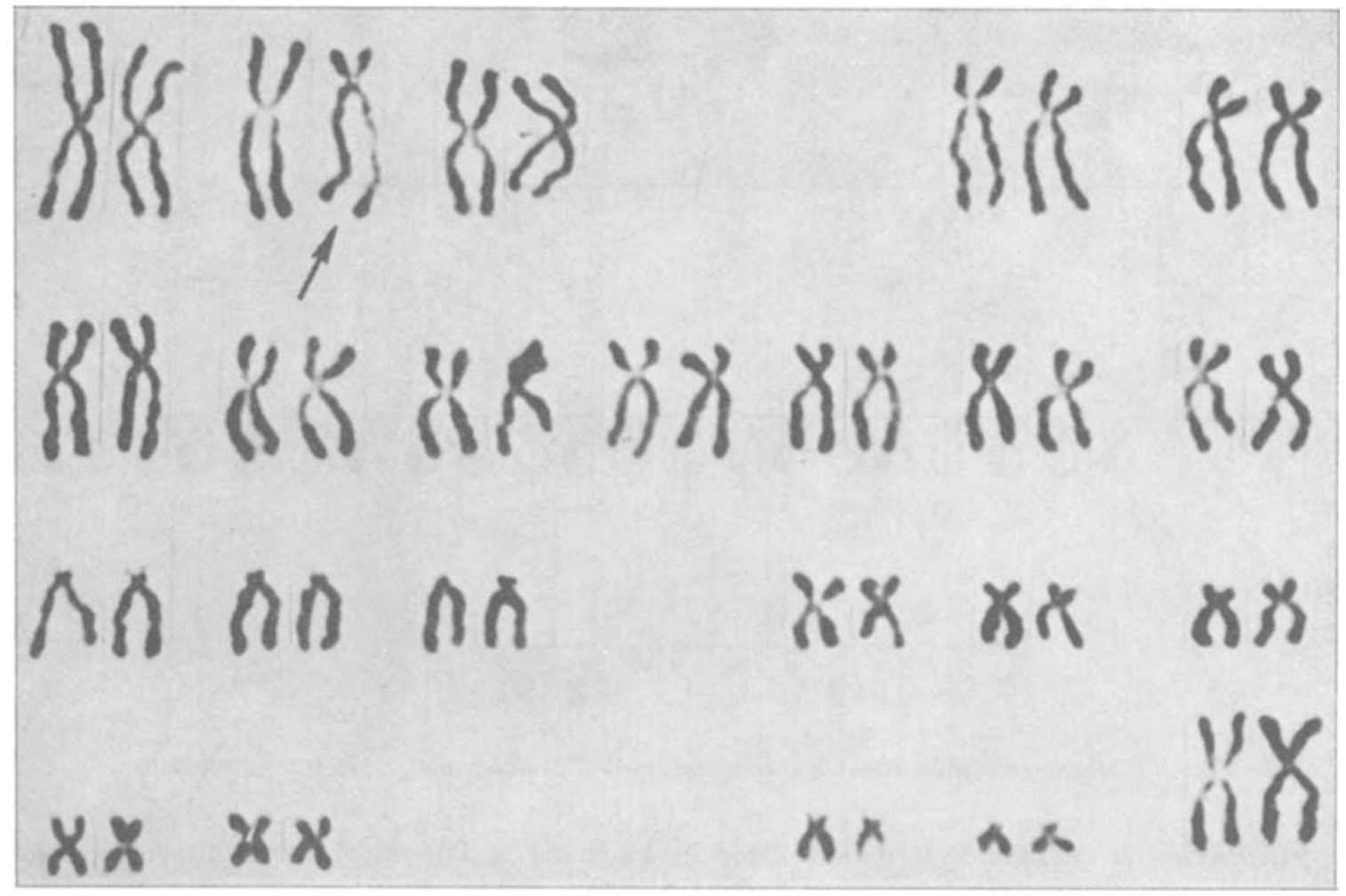

Fig. 1. Karyotype of an individual from family 10854. One chromosome of the number 2 pair has a more terminally placed centromere.

individual was assigned on the basis of the population gene frequencies listed in Table 1. It was assumed that the abnormal number 2 chromosome occurred in only one of the individuals in the first generation (I. 1 and I. 2) and did not occur in III. 22. Once the probability expression for the pedigree was derived, the relative probability (probability ratio) for any specific recombination fraction, $c$, was obtained by dividing the solution of the probability expression (cf. Appendix II) using the specific value of $c$ by the solution obtained when $c=0.5$ (no linkage). The average probability ratio was estimated by Simpson's rule, and the probability of free recombination, assuming that the a priori expectation of finding linkage is approximately 1 in 22 in man, by the formula of Smith (1959). 
RESULTS AND DISCUSSION

A photograph of a representative karyotype, illustrating the more terminally placed centromere in the abnormal chromosome, is shown in Fig. 1. A similar karyotype was found in a total of seventeen individuals, and a pedigree which demonstrates the segregation of the abnormal chromosome is drawn in Fig. 2. Assuming that only one individual in generation I possessed the abnormal chromosome, and omitting the proposita (IV. 4), her mother (III. 8), and her grandmother (II. 4), there are fourteen individuals who received the marker chromosome from a carrier parent and twelve who did not. Salt-losing adrenogenital syndrome occurred in IV. 2 as well as the proposita, but other members of the family appeared normal.

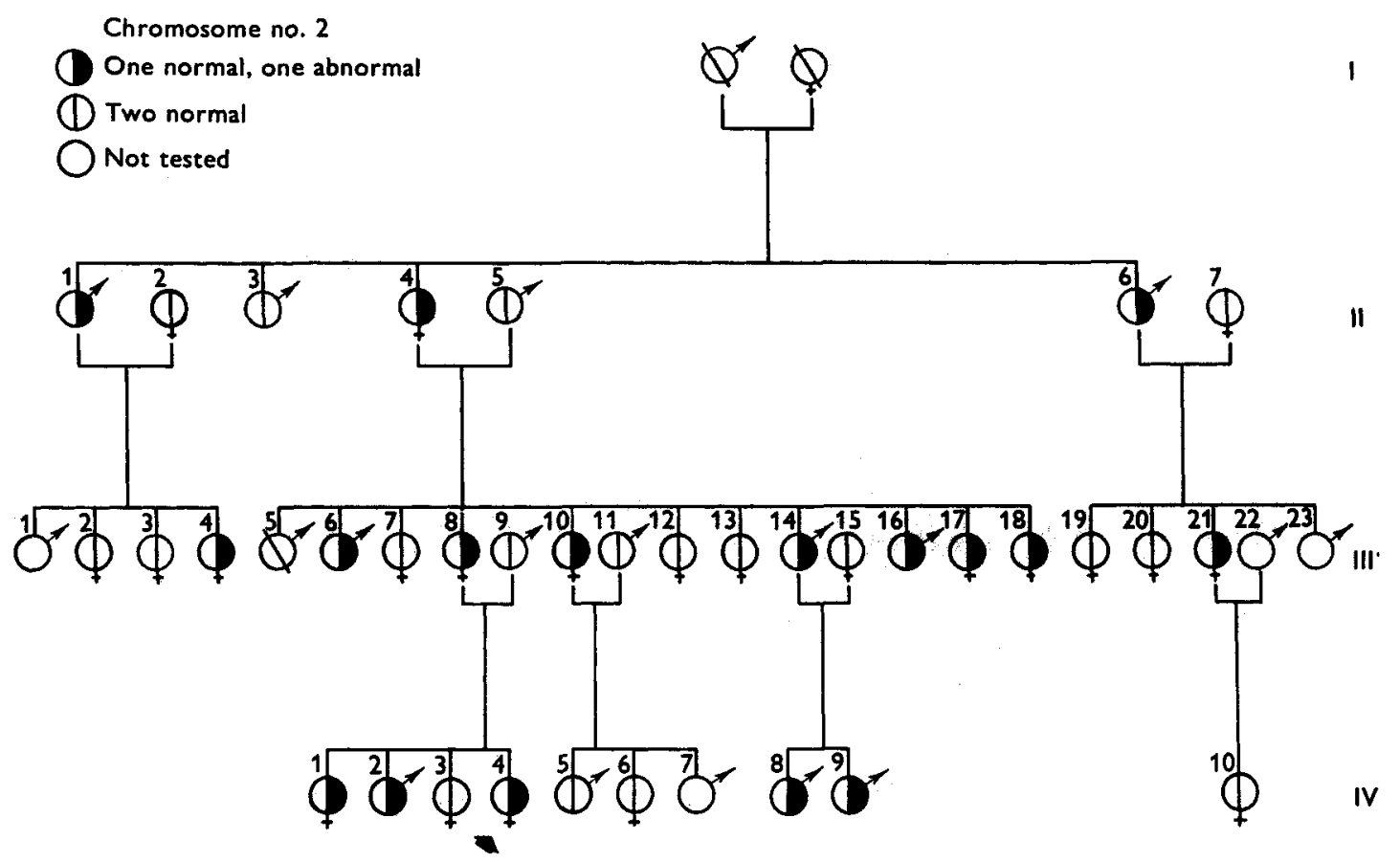

Fig. 2. Pedigree of family 10854 showing segregation of abnormal number 2 chromosome.

Phenotypes in eighteen systems are listed in Appendix 1. The data proved informative for linkage with respect to twelve genetic loci, and, except for the Kidd and Lewis systems, the results of linkage analysis of each of these loci with regard to the abnormal number 2 chromosome are shown in Table 1 (probability expression listed in Appendix 2). At the $95 \%$ level of confidence, linkage with 6-PGD is not expected at $c<0.05$, with Gc, Hp, PGM, and Se at $c<0 \cdot 10$, with ABO at $c 0 \cdot 15$, with MNSs at $c<0 \cdot 20$, and with Fy at $c<0 \cdot 30$. Formal analysis of the probability of random segregation of the marker chromosome and alleles at the Kidd and Lewis loci is quite tedious because of the large number of individuals for whom the genotype is unknown. However, an estimate of $L$ can be quickly obtained by considering only those individuals in generations III and IV for whom the genotype is completely known. In the Kidd system there are five informative offspring (III. 2, 3, 4, 16; IV. 10) and the estimate of $L$ is $b^{3} c^{2}+b^{2} c^{3}$. In the Lewis system there are seven informative offspring (III. 3, 4, 6, 7, 10, 16; IV. 4); the estimate of $L$ is $b^{5} c^{2}+b^{5} c^{2}$. Thus, it is clear that in neither system is close linkage likely. There 
is little evidence for and no evidence against location of the locus for salt losing adrenogenital syndrome on chromosome number 2 .

Although linkage of the abnormal number 2 chromosome was not demonstrated at the $5 \%$ level of confidence with any of the genetic loci listed, it should be noted that the probability for free recombination with the acid phosphatase locus is only 0.55 . Since there were no recombinants in the small number of informative offspring, future studies with respect to this locus and the number 2 chromosome are clearly indicated.

\section{SUMMARY}

A pericentric inversion of chromosome number 2, segregating in the expected Mendelian ratios, has been found in seventeen individuals of one family, all of whom, except for adrenogenital syndrome in the proposita and one sib, are apparently normal. Genetic linkage of the marker chromosome with any of twelve loci was not established. However, no recombinants were found in a few individuals informative for linkage with respect to the acid phosphatase locus, suggesting the desirability of further investigation of the possibility that the acid phosphatase locus may reside on chromosome number 2 .

We thank Dr George Lowrey for clinical data on the proposita and her siblings and Mrs K. Ryan for technical assistance.

\section{REFERENCES}

CARr, D. H. (1962). Chromosome anomalies with special reference to Klinefelter's syndrome. Trans. Am. Ass. Geneto.-Urin. Surg. 54, 9.

Cohen, M. M., Capparo, V. J. \& Tokagi, N. (1967). Pericentric inversion in a group D chromosome (13-15) associated with amenorrhoea and gonadal dysgenesis. Ann. Hum. Genet., Lond. $30,313$.

DeGrouchy, J., Emerit, I., Corone, P., Vernant, P., Lamy, M. \& Souliw, P. (1963). Inversion péricentric probable du chromosome no. 2 et malformations congénitales chez un garçon. Annls Génét. 6, 21.

Haldane, J. B. S. \& Smith, C. A. B. (1947). A new estimate of the linkage between genes for colour-blindness and haemophilia in man. Ann. Eugen. 14, 10.

Jacobs, P. A., Cruickshank, G., Faed, M. J. W., Fracklewicz, A., Robson, E. B., Harris, H. \& SutherLAND, I. (1967). Pericentric inversion of a group C autosome: a study of three families. Ann. Hum. Genet., Lond. 31, 219.

Moorehead, P. S., Nowell, P. C., Mellman, W. J., Buttips, D. M., \& Hungerford, D. A. (1960). Chromosome preparations of leukocytes cultured from human peripheral blood. Expl Cell Res. 20, 613.

NANCE, W. E. \& ENGEL, E. (1967). Human cytogenetics: a brief review and presentation of new findings. J. Bone Jt Surg. 49-A, 1436.

Schmid, W. (1967). Pericentric inversions. J. Génét. hum. 16, 89.

Sмrтн, C. A. B. (1959). Some comments on the statistical methods used in linkage investigations. $A m$. $J$. Hum. Genet. 11, 289.

Soudek, D., Laxová, R. \& AdÁmek, R. (1968). Pericentric inversion in a family with a $21 / 22$ translocation. Cytogenet. 7, 108.

Summit, R. L. \& ATnIP, R. L. (1966). Chromosomal aberrations with normal phenotype: four examples. Ala. J. Med. Sci. 3, 483. 


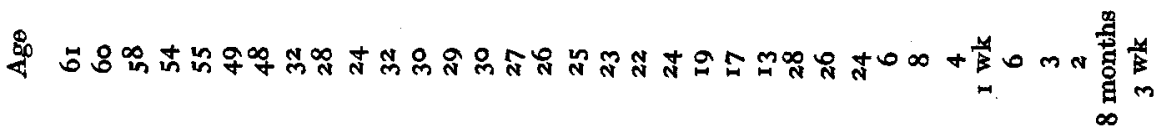

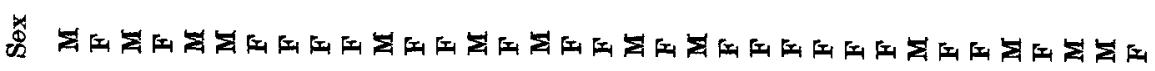

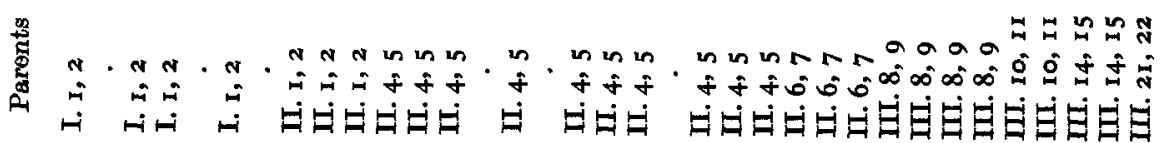

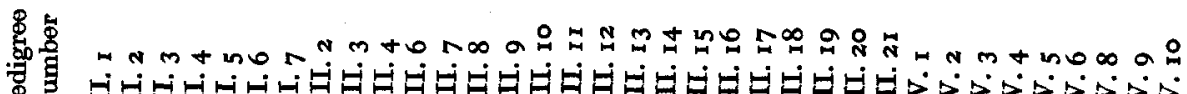

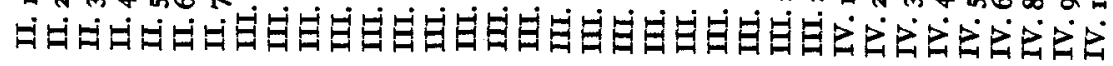




\section{APPENDIX 2}

Expressions used in calculation of the Probability ratios for various values of the recombination fraction

Probability expression

(terms which do not contribute to the probability ratio have been

Locus

Ge $c$

Hp $\quad b^{2} c^{2}$

$\mathrm{PGM}_{1} \quad\left(p q / 2+q^{2} / 8\right)\left(b^{5} c^{3}+b^{3} c^{5}\right)+\left(p^{2}+p q / \mathrm{I} 6\right) b^{2} c^{2}$

AP $\quad p\left(b^{8}+b^{4} c^{4}\right)+(q / 4+r / 8)\left(b^{7}+b^{4} c^{3}\right)+(p / 8) b^{4}$

6-P'GD $\left(p q / 2+q^{2} / 8\right)\left(b^{9} c^{3}+b^{7} c^{5}\right)+\left(p^{2}+p q / \mathrm{r} 6\right) b^{6} c^{2}$

ABO $\left(p+q / 8+3^{r / 4}\right) b^{7} c^{4}+(p+q / 4+r / 2) b^{5} c^{6}+\left(q / 8+3^{r} / 4\right) b^{3} c^{8}+(p / 8) b^{2} c^{5}$

MNS $\quad b^{13} c^{7}+b^{12} c^{8}+b^{7} c^{18}+b^{6} c^{14}$

Rh $\quad(p)\left(b^{8} c+b^{4} c^{5}\right)+(q / 4+x / 8)\left(b^{7} c+b^{4} c^{4}\right)+(p / 8) b^{4} c$

Fy $\quad\left(p^{2} / 2+q^{2} / 2\right) b^{10} c^{10}+(p q / 2) b^{9} c^{9}+\left(p^{2} / 2+q^{2} / 2\right) b^{8} c^{12}+$

Se $\quad\left(c^{2}+x\right)\left[(p / 4) b^{7} c^{2}+(3 p / 4+q) b^{6} c^{3}+(5 p / 8) b^{5} c^{4}+p b^{4} c^{5}+\right.$ $\left.(p / 4) b^{8} c^{6}+(q / 16) b^{2} c^{3}+(p / 2) b^{2} c^{7}\right]$
Alleles

$$
\begin{aligned}
& p=\left[\mathrm{PGM}_{1}^{1}\right], q=\left[\mathrm{PGM}_{1}^{2}\right] \\
& p=\left[\mathrm{P}^{\mathrm{b}}\right], q=\left[\mathrm{P}^{\mathrm{a}}\right], r=\left[\mathrm{P}^{\mathrm{e}}\right] \\
& p=[\mathrm{Pd}], q=\left[\mathrm{Pd}^{\mathrm{B}}\right] \\
& p=[\mathrm{O}], q=[\mathrm{B}], r=[\mathrm{A}] \\
& p=[\mathrm{CDe}], q=[\mathrm{cde}], x=\mathrm{I} \cdot p \cdot q \\
& p=\left[\mathrm{Fy}^{\mathrm{s}}\right], q=\left[\mathrm{Fy}^{\mathrm{b}}\right] \\
& p=[\mathrm{Se}], q=[\mathrm{se}]
\end{aligned}
$$

